\title{
Prisoners' views of injecting drug use and harm reduction in Irish prisons
}

\author{
Jean Long ${ }^{\mathrm{a}, *}$, Shane Allwright ${ }^{\mathrm{a}, 1}$, Cecily Begley ${ }^{\mathrm{b}, 2}$

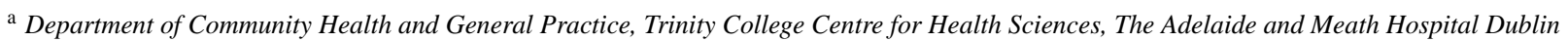 \\ Incorporating The National Children's Hospital, Tallaght, Dublin 24, Ireland \\ b School of Nursing and Midwifery Studies, Trinity Centre for Health Sciences, St. James's Hospital, James's Street, Dublin 8, Ireland
}

Received 7 November 2002; received in revised form 6 June 2003; accepted 20 June 2003

\begin{abstract}
Drug misuse and hepatitis $\mathrm{C}$ are known to be endemic in Irish prisons. Using a grounded theory approach, this qualitative study sought to examine prisoners' views of drug injecting practices and harm reduction interventions in Dublin prisons. Thirty-one male prisoners were interviewed (16 injecting drug users and 15 non-injectors). Two themes relevant to drug use practices emerged. Respondents described increased health risks related to injecting drug use during detention and associated with a prison environment. These included: the low availability of heroin which encouraged a shift from smoking to injecting; the scarcity of injecting equipment which fostered sharing networks far wider than outside prison; inadequate injecting equipment cleaning practices; and the rent of needles and syringes in exchange for the drugs. Both non-injectors and injectors interviewed supported harm reduction interventions in prison and felt that the range of drug services available in prison should mirror those currently available in the community, although half opposed or had reservations about syringe exchange in prison. Prisoners' viewed their time in prison as an opportunity to address substance misuse related problems; health professionals should not miss this opportunity. (C) 2003 Elsevier B.V. All rights reserved.
\end{abstract}

Keywords: Prisoners; Injecting drug use; Blood-borne viruses; Harm reduction

\section{Introduction}

In 1994, Turnbull et al. published a study that examined drug use in English prisons (Turnbull, Stimson, \& Stillwell, 1994). They found that cannabis and heroin were the most commonly used drugs in English prisons, with cannabis used daily and heroin weekly. They reported that drugs were brought into prison via a variety of outside contacts (visitors, court appearances and temporary release) and that drugs were shared with other prison inmates. This arrangement was mainly reciprocal or occasionally altruistic (giving another prisoner some heroin to alleviate symptoms of withdrawal). They found that episodes of violence were associated with drug use in prison. They reported less frequent injecting in prison than outside prison, but higher lev-

\footnotetext{
* Corresponding author. Present address: Drug Misuse Research Division, Health Research Board, 73 Lower Baggot Street, Dublin 2, Ireland. Tel.: +353-1-676-1176; fax: +353-1-661-8567.

E-mail addresses: jlong@hrb.ie (J. Long), sllwrght@tcd.ie

(S. Allwright), cbegley@tcd.ie (C. Begley).

${ }_{1}$ Tel.: +353-1-608-2293; fax: +353-1-403-1212.

2 Tel.: +353-1-608-2693; fax: +353-1-403-1212.
}

els of sharing injecting equipment among larger cohorts of individuals. This latter finding is in keeping with other studies (Allwright et al., 2000; Bird, Gore, Cameron, Ross, \& Goldberg, 1995; Bird, Gore, Jolliffe, \& Burns, 1992; Carvell \& Hart, 1990; Dolan, Hall, \& Wodak, 1996; Gore et al., 1995; Gore, Bird, Burns, Ross, \& Goldberg, 1997; Long et al., 2001; Malliori et al., 1998; Turnbull, Dolan, \& Stimson, 1991). Turnbull et al. also reported that needles and syringes were rarely if ever disposed of in prison but were passed on to other inmates on release (Turnbull et al., 1994). Several studies have reported actual or probable transmission of blood-borne viruses in the prison environment (Crofts et al., 1995; Haber et al., 1999; Hutchinson et al., 1998; Taylor et al., 1995).

In Ireland, in 1998 and 1999, Allwright et al. and Long et al. conducted national surveys to estimate the level of infection with blood-borne viruses (hepatitis $\mathrm{B}$, hepatitis $\mathrm{C}$ and HIV) in the Irish prison population and to identify risk factors for infection (Allwright et al., 2000; Long et al., 2001). Hepatitis $\mathrm{C}$ infection was shown to be endemic in Irish prisons: prevalence rates among prison inmates were $37 \%$ overall and $81 \%$ in injecting drug users (Allwright et al., 2000). The most important risk factor for infection was injecting 
drug use. These surveys showed that injectors were more likely to share injecting equipment inside prison than outside prison, and found that sharing needles inside prison was associated with an increased risk of hepatitis C (Allwright et al., 2000; Long et al., 2001). These studies also found that as time spent in prison increased, so did the risk of testing positive for hepatitis $\mathrm{C}$. The qualitative study presented here sought to explain the risk factors identified in these two quantitative surveys through exploring prisoners' perceptions on whether and how injecting practices differed inside and outside prison.

An additional reason for this study was that the Irish Government Department of Justice, Equality and Law Reform review of prison-based drug services in Ireland had consulted all stakeholders, except prisoners (Irish Prison Service, 2000). In order to remedy this oversight, this study sought to document prisoners' suggestions (both injectors and non-injectors) for harm reduction interventions so as to reduce the risk of viral infection in Irish prisons.

\section{Methods}

The study employed qualitative research methods using a grounded theory approach to explore respondents' lived experiences of injecting drug use and heroin addiction in prison (Polit \& Hungler, 1999; Streubert Speziale \& Carpenter, 2003). The study examined injecting drug use in the prison environment and the prison service's potential for response by considering the perspectives of both injector and non-injector prisoners (person triangulation) (Denzin, 1989). In line with a grounded theory approach, the interviewees were considered expert witnesses in relation to injecting drug use and prison life.

\section{Sample sites}

The prisons were selected from the eastern region of Ireland as injecting drug use is concentrated in this region. The Director of Prison Medical Service suggested that the research team use prisons other than those in the Mountjoy Complex because several other research studies had been conducted with prisoners detained in this prison complex, and it was important to consider the views of prisoners detained elsewhere. Wheatfield Place of Detention, Dublin and Portlaoise Prison, Co. Laois (45 miles from Dublin) were selected as it was believed that these prisons would provide an adequate number of injectors who injected while in prison as well as non-injectors who had observed injecting. The majority of prisoners in Wheatfield Prison and Portlaoise Prison would have been committed initially to Mountjoy Male Prison or St. Patrick's Institution. Conducting the study at two prison sites ensured an adequate number of non-injectors as well as enabled the documentation of prisoners' perspectives at different sites (place triangulation) (Denzin, 1989). The study was conducted independently of the Department of Justice, Equality and Law Reform and the individual prison authorities, although their permission and co-operation was sought and provided.

\section{Participants}

A purposive sampling method was employed. Two types of respondents were sought, injectors and non-injectors. Prisoners who had never injected illicit drugs were asked if they had observed injecting drug use in prison and if so, to describe what they had observed. Approximately 30 respondents were deemed necessary to achieve maximum saturation, but 31 (16 injectors and 15 non-injectors) were interviewed. The respondents were detained in Portlaoise Prison (15) and Wheatfield Place of Detention (16). All respondents were over 18 years old, had spent time in the Mountjoy Complex of prisons (where there is a high prevalence of heroin use), and were willing to converse and capable of talking about drug using experiences. Sex offenders and political or high security prisoners were excluded as they were separated from the general prison population and were deemed unlikely to have extensive experience of injecting drug use while in prison.

\section{Data collection}

Data were collected through in-depth interviews using a semi-structured questionnaire and an interview topic guide. The use of the topic guide (rather than a structured questionnaire) allowed the interviews to include a wider range of participant experiences and views. Data collected in this way seeks to describe a concrete lived experience (Poland, 1999).

The interviews were held in a quiet room (classroom in Portlaoise and visitors' room in Wheatfield) with an assigned prison officer waited outside the closed door, and took place over a period of 5 weeks in 2000. The first four interviews were undertaken as pilot interviews. When undertaking interviews, the purpose of the study and methods were explained (including the taping of the interview) and the voluntary nature of the study was stressed. The interviewer (J.L.) introduced herself as a health professional, independent of the prison authorities. All interviewees gave signed consent to participate. Field notes were kept, which helped to place the interviews in the context of their surroundings and allowed the interviewer to record new issues to be explored in future interviews.

All respondents were asked 12 closed questions pertaining to socio-demographic characteristics, prison history, illicit drug use and alcohol use. The respondents who had a history of injecting drug use were then asked about drug use outside prison, drug use inside prison and the dangers of injecting drug use. The topics differed slightly for non-injecting respondents: they were asked about their personal experience of drug use outside and inside prison, observations on injecting drug use in prison and fears associated with inject- 
ing drug use. All respondents were asked "what action is required by the prison authorities to deal with drug misuse in prison?".

\section{Data analysis}

Interview tapes were transcribed verbatim. Written notes supplemented what was said during the interviews and Silverman's transcription symbols were employed to ensure consistency in transcription style (Poland, 1999). The interviewer (J.L.) listened to each tape three or four times, initially (during the interview period) to identify new issues and later to ensure that the transcripts accurately reflected the tapes.

Six transcripts (three each from injectors and non-injectors) were coded by two team members (J.L. and C.B.). Where codes differed, these were discussed and an agreed compromise adopted. The 31 transcripts were entered into 'Ethnograph' (Seidel, 1998) and coded by J.L. An audit trail (Appleton, 1995) was kept, showing how codes led to categories and categories formed the themes. Five overall categories emerged and two themes were identified from these categories. Participants' narratives were used to illustrate these themes (Koch, 1994). Negative cases (Mariano, 1995) were identified and acknowledged, but did not contradict the main findings.

\section{Ethical approval and confidentiality}

The study had ethical approval from the Trinity College Public Health Ethics Committee. Confidentiality was assured and no prisoners' names were recorded. Following each interview, reference to the respondents' name on the taped interview was removed and replaced with a number. The tapes were cleaned once the interviews had been transcribed and verified.

\section{Findings}

\section{Participant characteristics}

All 31 of the respondents were male. The median age (range) of the respondents was 26 (18-37) years. Two thirds $(21 / 31)$ of the participants said that they normally resided in Dublin. Only two respondents had completed second level education. All of the prisoners interviewed had been sentenced. Four (13\%) of the 31 respondents reported that this was their first imprisonment. Over two thirds $(21 / 31)$ of the participants said that they had spent at least 3 of the last 10 years in prison. Three quarters (23/31) of the prisoners described their crime as drug or alcohol related.

Most respondents started to use illicit drugs when they were between 13 and 15 years old, and they reported a similar pattern of progression in drug use. All of the re- spondents reported taking illicit drugs at some time in their life. Three respondents reported having used one illicit drug only (cannabis). Sixteen participants reported that they used heroin more frequently than other drugs, while eight reported using cannabis more frequently. Of the remaining seven respondents, three had taken cocaine more frequently than other drugs and the others had used ecstasy. Three quarters of the respondents said that they had taken heroin $(24 / 31)$ or ecstasy $(24 / 31)$ at least once. Five $(16 \%)$ respondents stated that they were dependant on alcohol prior to imprisonment. Five (16\%) participants said that they were using heroin at the time of the interview.

\section{Key themes}

Two themes relevant to drug use emerged from the analysis of interview transcripts; first, injectors take risks during detention that they would not take outside prison; second, prisoners want and will support programmes to address drug misuse. We explore these findings below.

\section{Injectors take risks during detention that they would not take outside prison}

\section{Context}

Eleven respondents stated that hash (cannabis) and heroin were available in prison. One respondent stated that cocaine was also available while another contradicted this statement. The respondents said that drugs (including heroin) were more easily available in the Dublin prisons (Mountjoy Male Prison, St. Patrick's Institution, and Wheatfield Place of Detention) than in Portlaoise Prison. According to the respondents, availability was highest in Mountjoy Male Prison and the 'drug situation' was 'out of control' in this prison. Respondents used drugs to escape from the reality of their life, to be part of a particular group of people and to relieve boredom in prison:

I think a lot of heroin use begins in the prisons. Once the gates close behind you and you have no escape, people look to escape through heroin. (NONA1)

Is it very difficult to be off heroin? (J.L.)

It would be, it was when I was in the last prison ((Mountjoy Male)) but, down here ((Portlaoise Prison)) it's not, no. (IDUA3)

Why was it difficult in the last prison? (J.L.)

Because there's too much of it around. Thinking about it all the time, people going around stoned. (IDUA3)

At the time of the study, inadequate detoxification on entry to Mountjoy Male Prison led to unnecessary suffering in this prison: prisoners addicted to heroin were offered a 2-week 
methadone detoxification programme using an (inadequate) decreasing dose of methadone from 25 to $5 \mathrm{mg}$.

How would withdrawals have differed in prison from the outside? (J.L.)

Em, it didn't differ at all, you're going through the same thing. The only ... thing about being in jail is when you're locked behind a cell and you just can't open that door and go walking when things is getting on top of you, that' $\mathrm{d}$ be the main difference from here to the outside.... (IDUB1)

The uptake of the short detoxification course indicated that prisoners were willing to substitute heroin with methadone; 12 injectors and one smoker interviewed said that they had availed of this short detoxification course known as a 'crash course'; but most had used heroin throughout, due to an inadequate methadone dose.

\section{Low availability of heroin encouraged the change from smoking to injecting}

Overall the low availability of heroin in prison influenced the change from smoking to injecting. According to the respondents, a small but significant (3) number of them started to inject in prison. Some of the respondents who smoked heroin were asked if they had any problem satisfying their heroin habit in prison. It was clear from the respondents that they were not forced to inject rather than smoke heroin in prison, but when supplies were low, a group would agree that if they injected, then lower quantities of heroin would be required to experience a 'buzz'. This is generally how the decision to inject rather than smoke was made.

And why did ... why did you start injecting in here? (J.L.)

... I was only in ((prison)) off the streets ... at the time and I had a couple of, em, mates here... and they were getting heroin in and they were more or less saying "well we haven't really got it to give it to you to smoke, but there's a turn on ((heroin taken by injection)) there if you want it", you know what I mean? Like "you can have a turn on, but there's not enough there for you to have a smoke the way you smoke the stuff".... (IDUA10)

... I started using ((injecting)) heroin again, like intravenously, only for about 3 or 4 months and then I went back smoking, ... was only using it intravenously 'cos I was in prison... (IDUA13)

If there's a lot of heroin there to take, it's okay for everybody to smoke right, and they have a little habit ((addiction)) in prison. Then there comes a day when there's only enough for three people and they say look if we all have a turn ((injection)) and then we'll all still get a buzz out of it and that's how people end up going from smoking to injecting. It's because there's not enough there and they feel that their need to get that bit of heroin like, even if they have to use ((inject)) it. (NONB2)

Those who own a needle and syringe rent them to others as a means of acquiring drugs to maintain a habit

Injectors reported that the methods used to fund drug misuse outside prison (robbery and selling drugs) differed from the methods used in prison (bartering and owning injecting equipment). As the following extracts illustrate when outside prison:

... I started dealing in heroin and... 3 months it was, when there wasn't much around, and I was making over $£ 1,000$ a day, but I had no money to show for it, I was using it all ((to fund my heroin habit)). (IDUA5)

Using the last two or three year. Gone robbing and all that to feed me habit like, so I got locked up, and, er, that's it really. (IDUB8)

I used to sell it and all, you know?, so I was doing well and all, I had money and all but then I started getting into cocaine and all, you know? I lost like... I had no money or nothing and er,... every morning waking up dying sick, saying "ah here I am going to have to rob to get any ((money)), where am I going to get money today?"... (IDUB9)

Whereas injector respondents said that if an injector owned a syringe and needle in prison he could rent it to other injectors in return for heroin, and thereby, maintain his habit:

You'd, yeah, you'd, er, there's be a bit of bartering going down here. You'd give someone a bit and the day you'd have nothing you'd be depending on them.... (IDUA13)

Em, it's just like the lads on the landin' like. Like they're good ... they're sort of good friends of mine like. I get on well with them like (NONB15)

If you own a syringe in here you can feed a habit, you can keep your habit going 'cos every day of the week someone's going to come to you with heroin and say "listen, I have gear, do you want a bit of it for a lend of your syringe" and that's the way things work, you know? (IDUB1)

Scarcity of injecting equipment meant that sharing circles were far wider than outside prison

A number of injectors said that they had taken risks in relation to sharing during detention that they would not take outside prison. Almost all injectors said that outside prison they obtained their injecting equipment from a needle exchange facility and one-third reported that when outside prison they had never shared injecting equipment. Most respondents who shared injecting equipment outside prison 
did so with one or two other people only, while two had shared indiscriminately:

You know?, so I always, from day one, ... had my clean needles an' all, you know? I never used after anybody. (IDUA2)

... I probably always inject with me girlfriend, you know like?... (IDUB9)

Yeah, I share with my brother... and girlfriend. (IDUA10)

On the other hand, when respondents were imprisoned, they consistently reported an increase in the number of times that they had shared injecting equipment as well as the number of people with whom they shared:

Yeah well, ah yeah, well it's obvious the risk factors are an awful lot higher for the simple reason is, there's only a certain amount of needles and syringes in prison. (IDUA11)

In prison..., I'm not lying you want to see the state of the works ((syringes and needles)).... The spikes ((needles)) ... do be bent... about six people like using them. There's about 30 people on a landing and I'd say between the three landings there's only about four or five syringes ... and half of them on the landing would be using the syringes, you know?, very dangerous (IDUB9)

There' $d$ be people I'd be wary of sharing with, but there'd be days ((in prison)) when things would be that bad that you'd have to use it 'cos you'd be that sick ((suffering from withdrawals)), that craving, you know? Well, you'd know people who'd have one ((syringe and needle)) and you'd approach them and ask them for a lend of it. Now you'd know yourself that it's probably after being around the prison for years, but you'd just say ah I'll put a bag on it and steep the spike in bleach for half an hour and it'll be alright. (IDUB7)

You mentioned put a bag on it. Put a bag on what? (J.L.)

On the barrel ((syringe)). On the plunger bit of the barrel put a bag ((piece of a plastic carrier bag)) onto it and it stops it from whatever, you know? just to be safe, 'cos if the virus was on the barrel, put a bag over it. (IDUB7)

\section{Cleaning practices for injecting equipment were inadequate}

According to the respondents, shared injecting equipment was inadequately cleaned and sterilised. Six respondents washed the equipment in cold water only, a further five used diluted bleach to wash it and a small number steeped the equipment in bleach after washing it. Four respondents said that they put a clean plastic bag over the plunger (within the syringe) to protect themselves from others' blood. Two respondents said that after cleaning the needle and syringe they left it to dry in the air for a few hours because they believed that this prevented them from acquiring one or more of the blood-borne viruses.

How would you clean them ((syringes and needles))? (J.L.)

Just water, just... give them a good rinse. (IDUA13)

And nowadays would you do anything differently, if you're going to inject? (J.L.)

Oh, er, like I'd put a bit of bleach on it or something, but, em, it wouldn't make any difference, no, I'd still just, I'd rinse it out before I'd do anything. ... E Er, I wouldn't use straight after anybody, even rinsing it, it's all to put me mind at ease, you what I mean? ... Just giving it a good clean out, put a clean bag ((piece of a plastic carrier bag)) on it. ... I wouldn't, ... use directly and I know like even a dirty needle and all that, but, er, I always managed to clean it out or to wait an hour or two before I used it ... (IDUA13)

Now they're not being cleaned proper for one, I know there's bleach and all down the jacks, you can bleach them, but they're only, they're putting plastic ((piece of a plastic carrier bag)) over, ... the plunger. They're putting plastic over it. You know?, they're not cleaning the plastic out proper either. They clean it, you know?, if there's no more plastic left, they turn it around and stick it back in. Now ... it's obvious ... there's still going to be some traces of blood, you know what I mean?, and they're not ever giving it any time to, er, how do you say?, die down. It's supposed to die after so long, isn't it?, outside the body. (IDUA11)

\section{Non-injectors reported observations were consistent with injectors reported practices}

The non-injectors in prison said that they knew which prisoners were current injecting drug users. Almost all non-injectors had observed injecting drug use in prison, and their reported observations of injecting were consistent with those reported by respondents who had injected in prison:

They're the "Desperate Dans" they're called. As in when someone goes on a visit ((relative or friend calls to visit them in prison)) an' they know he's gonna get somethin' there's about bleedin' fifteen of them waitin' for your man to come back an' they're all huddled kinda in a corner. They just stand out. Everybody knows, you know? (NONB13)

... out in the yard and there's, er, ten or twelve of them sittin' in circles, ganged up together and they've got two syringes and they're, they've got a milk carton ((for the water to clean the needle and syringe)) and they've water and probably a jam tray ((used to cook the heroin)) or 
somethin' and they're shootin' heroin on the jam tray and they're just dippin' it ((needle)) in the water and that's it, that's how they're cleanin' it and I mean you'd know straight away when you'd see the circle like. You'd know they're all over there bangin' up ((injecting)) like, you know? (NONB11)

\section{Prisoners want and will support programmes to address drug misuse}

All respondents were asked "what action is required by the prison authorities to deal with drug use in prison?" Respondents suggested a number of interventions including the organisation of daily activities in prison, drug awareness programmes, individual counselling sessions and harm reduction services. Non-injectors were in general understanding of the needs of injectors and both non-injectors and injectors supported positive action by prison authorities to address injecting drug use in prison. Both injectors and non-injectors want the range of drug services in prison to mirror the range currently available in the community but recognise that these will require strict supervision.

\section{Regular routine}

Many respondents said that a regular routine including a high quality education programme, a part-time occupation and a variety of recreation facilities had helped them tackle drug misuse in prison:

I use the gym. I use the school now and again and I'm working in the prison itself. ... So, I'm keeping myself active alright. I'm not just sitting around bored all day. It helps. (IDUB10)

I didn't take physeptone and for the first 6 months that I spent in Mountjoy, before I came down here to Portloaise, I didn't touch anything ((any drugs)). I started doing the gym and all. And, er, I came down here then and that's when I, when I took up a lot of, er, education and all, you know? And I think that's very important... (IDUA5)

I go to school, do the gym every now and again, but for others there's, em, like a lot of spare time on their hands and that's why you can't have too much time... You have to be doing something to keep busy otherwise you just go back into that slump of drugs, drugs, drugs. (NONW12)

\section{Counselling and support}

Prisoners appreciate information sessions on drugs, and according to respondents, individual counselling for self-selected prisoners was useful.

... I believe like to give up drugs it's down to the person, they have to decide that, it's really them like. $99 \%$ of people that go into, that go for counselling... go in for therapy or whatever they don't go in for the right reasons like, they're going in because so and so says it's the best thing to do or 'cos they have court ((to reduce the possible sentence)) or because they have charges or it's that they're looking for somewhere to lay the blame (NONB2)

A small number of respondents who had attended individual counselling in prison said that counselling (two to three times per week) had helped them to solve problems that they were experiencing.

Yeah, I get counselling here ... Well, if you have a problem like they work it out with you, do you know what I mean? Like, if I have a problem like, which I had, I had plenty of problems, everybody has problems. I mean you just, you talk to him about it you know and try to work a way around it. You focus in on that for today like just whatever you know. It was all right that way. (IDUB5)

Em, well for starters the person, the Welfare Officer himself he was down to earth, em, he was the type of person that... if he thought you were giving him bullshit, lying to him or anything he'd come out and say "well listen I think your lying to me"... Some people you can pawn off ... you can say to them well this is what's wrong with this, that and the other but you're getting away from the point altogether. This fellow used to sit down and you'd tell him, you'd say something to him, if he thought you were fucking him around or anything he'd come up to you and say listen you may leave and come back to me during the week when you want to talk to me honestly whatever, so he was just genuine and I could see he wanted to help. It helps to know that someone wants to help, do you know what I mean? (IDUW1)

The majority of respondents said that they would value individual counselling.

Yeah, I think it could be useful, yeah. Well it would probably put it in your mind to stay away from drugs you know when you get out. A few of my friends went to the detox places and stayed there you know and just came out clean. They're all right, all right, jobs and all. (NONW16)

A (further) small number of respondents had tried counselling but found that they could not talk about personal issues to a complete stranger. Two prisoners said that they would attend counselling if it would help them achieve a favourable review of the duration of their sentence.

Findings suggested that support groups in prison are ineffective if they are misused. For example, respondents reported that a session supported by Narcotics Anonymous is held in Wheatfield Place of Detention every month. None of the prisoners who attended these sessions reported that it had helped them to stay off drugs. It would appear that attendance at these sessions is not screened and often persons under the influence of drugs attend and disrupt proceedings. A more serious problem noted was that a small number of inmates requested counselling and were referred (inappropriately) by the prison management and/or other staff to these support sessions instead. 
And have you sought any help? Have you talked to anybody about that ((recent bereavement))? (J.L.)

Em, the only person I've talked to about it is the nun in here an', er, I talked to the governor as well like... And I asked the governor like was there any chance of getting help and he just told me for to go to the ... NA ((Narcotics Anonymous)) meetings and like I went to a few of them, but there's no point going to them because like the lads what goes to them they'd be stoned out of their heads like and they just go up for the laugh like... (NONB15)

And, have you gone to, em, to see the Probation and Welfare Officer or anybody else? (J.L.)

I seen the Welfare Officer yeah. (NONB15)

And what have they said? (J.L.)

Em, she just told me for to go to the NA as well an' I told her I said "there's no point like goin' to the NA" I said "because there's lads up there an' they're stoned out of their head" I said. (NONB15)

\section{Drug free units}

Several respondents (both injectors and non-injectors) said that they would welcome an increased number of regulated drug free units in Irish prisons. Portlaoise Prison was regarded as a drug free prison but it has a limited number of places that were generally reserved for prisoners who are deemed suitable for a $50 \%$ reduction in their length of sentence:

((Portlaoise Prison)) It's a, er, a drug, a drug free prison, supposed to be in any case. The part that I'm in anyway, there's no syringes in it. (IDUA3)

At the time of the interviews a drug free unit had just opened in St. Patrick's Institution for young offenders. According to the respondents, Mountjoy's Training Unit was a designated drug free area but places were limited. Respondents suggested that both Wheatfield and Mountjoy Male Prison should introduce large scale voluntary drug free units. Respondents reported that living in an environment where drugs were used was very difficult, if they wanted to stay off drugs.

Have separate units for people who don't use drugs, em, from my own experience, I've made a decision to be off drugs and I have been off drugs for, em, the last 17 months and er, I feel much better because of it but I would prefer to be away from drugs altogether because there's always that temptation even just to have a joint or something like that, em, but if it was a totally drug-free unit or something and if it was strictly kept that way I think that would help ... but I think more drug testing needs to be done in prisons, em, even for the likes of hash or whatever,... (NONB4)
Yeah, I've been on one of them in England, that's what I was saying. I was on one of them... I think that'd work, yeah 'cos I think there is a... there is a lot of young fellas want to give it up, but it's just it's in their face all the time and that landing I was saying that I was on in England every second day we were giving urines, every second day, so they knew. I mean any tampering with the urines or anything and that's it you were gone. (IDUB10)

Respondents said that drug free units should employ strict criteria and prisoners entering the unit should agree (in writing) to these criteria. Drug users wishing to enter should first have adequate detoxification. Respondents also said that random urine testing should be employed to monitor participants' drug status and those failing to observe the drug free status should be removed from the unit.

\section{Methadone maintenance}

The majority of the respondents supported a well-regulated methadone programme in all the Dublin prisons. According to the respondents, the positive aspects of a methadone programme were that it prevents the spread of infection; reduces or prevents injecting; facilitates withdrawing from heroin; and had a stabilising effect in the prison:

Yeah, I think ((methadone maintenance)) would be a good, I think that'd be a good way of getting an awful lot of people that's, that has prison habits if they started a maintenance instead of a quick detox because at the end of the day when you come off detox you're still ((suffering from withdrawals and want heroin)) (IDUA7)

It is a good thing, from what I've seen on the maintenance.... I've seen a lot of people that've been on the maintenance have cut down a lot on drugs because if they'd have taken $60,70 \mathrm{ml}$ of physeptone well then heroin's no good to them any more, h'mm? I think they're just two drugs that just don't go with each other, you know? One drug cuts the other out like, I think, h'mm? (NONB11)

I'd rather see them on that ((methadone)) than dying sick you know. 'Cos I know what it's like, it's not nice.... (NONB16)

A small number of injector and non-injector respondents expressed mixed feelings. They said that methadone maintenance would prevent persons having withdrawals and violent incidences, but inmates may use both heroin and methadone, or inmates may not opt for methadone as it does not have the same 'buzz' as heroin. Some respondents reported that withdrawals from methadone were more painful than withdrawals from heroin.

One injector and five non-injectors would not support a methadone maintenance programme in prison. These respondents said that heroin users may use both or that the prison authorities may use methadone as a 'control mechanism'. 
Well I can't say I genuinely say anyone taking methadone for the benefit, they use it and they use heroin you know what I mean.... And I've been told by people that use it that it's harder to get off the methadone than it is the heroin. (NONA9)

Like, they're talking about bringing this maintenance methadone course in and anybody that wants be on it, you know? ... But all that, all that'll do, that'll just keep everybody stoned $24 \mathrm{~h}$ a day, every day. You know what I mean?, so like they're still giving drugs, you know what I mean? They're not, they're not tackling the drug problem. They'll be still going around stoned on methadone every day. (IDUA8)

\section{Needle exchange}

There are no needle exchanges in Irish prisons and respondents were divided on support for needle exchange in prison. Seven injectors and five non-injectors would support a needle exchange in prison while two injectors and four non-injectors had mixed feelings. Equal numbers of injectors (6) and non-injectors (6) would oppose needle exchange in prison. Some respondents reported that the prison officers would not allow needle exchange in prison.

... The drug problem is there, I think they should give out clean needles.... Know what I mean? That's my opinion. That's what they should do because you know the way they're sharing and all? an' I'd say the best part of half of that place up there has the virus... (IDUA11)

What would you think about giving them clean needles, and syringes? (J.L.)

Ah, it's probably a good idea cos there's no point in saying that it's going to encourage them cos they're going to do it anyway, do'ya know what I mean, (NONA15)

Hmm... And do you think that that could be dangerous for people who are injecting if there was a lot of clean needles given out to prisoners, ... say to people like yourself? (J.L.)

No, cos if they're going to do it they'd do it anyway, cos they have needles there like, do'ya know what I mean, they have needles there, there could be as much dirty needles there already as you give them clean needles, you know what I mean, so they have them there anyway like, but ah, but I don't think that'd be a risk. (NONA15)

There's two sides to that coin, you know?.... I think it'd stop a lot of the drugs, not a lot ((of drugs)), sorry, stop a lot of AIDS spread, you know? Em, they shouldn't have drugs in prison, they shouldn't have to need to hand out needles, you know? ... To prisoners, you know what I mean? But the fact is the problem is there and like they'll have to do something. (IDUA10)
What would you think about it in prison? (J.L.)

Needle exchange? Oh Miss, Miss, Miss, Miss T'would be bad, bad news. I would definitely now tell ya out, like y'know wha I'mean I know they'd probably love it, because I mean, getting needle exchange in prison, that gives them the, a licence to inject. (NONA6)

A number of respondents said that needle exchange would reduce the spread of infection in prison, but a significant number of these feared that the needles could be used as weapons in disputes with prison officers and other prisoners. A small number thought that it would encourage even more prisoners to start injecting in prison.

Why not?((there should be no needle exchange)) (J.L.)

Just... it's for the officers safeties as well, you know like?, in case an officer gets jabbed or anything, but just for other reasons like, er, people, like who wear jewellery and all, they'd take your jewellery and all off you, and with a syringe as well if they were giving it out, you know? It'd be ... I think it'd be mad to give out syringes in prison. (IDUB9)

I don't know if it would work, em, from a safety point of view, em, I think that they could be used as weapons against the officers and they don't even have to be used, there's always that fear that they might have been used. (NONB4)

\section{Discussion}

This study presents, for the first time, prisoners' views of the extent of the drug problem in Dublin prisons and their suggestions for interventions to address this issue. Their suggestions indicate that prisoners could be an important resource when planning health services and that their needs are realistic and humane. The study provides contextual data illustrating how sharing is a risk factor in the Irish prison environment. In addition, the study also describes the move in prison from smoking heroin to injecting. It is clear that these practices (starting to inject, sharing injecting equipment frequently with a larger cohort of individuals and inadequate cleaning and sterilising of injecting equipment) increase the likelihood of contracting HIV, hepatitis B and, in particular, hepatitis $\mathrm{C}$ in prison. The validity of the study findings are indicated by the similarity of the findings to those from other studies (Bird et al., 1992, 1995; Carvell \& Hart, 1990; Dillon, 2001; Dolan et al., 1996; Gore et al., 1995, 1997; Malliori et al., 1998; Turnbull et al., 1991, 1994).

At the time the data presented in this paper was collected, Dillon (2001) conducted an exploratory study examining drug use among prisoners $(n=29)$ in Mountjoy Prison Complex, Dublin. Where there was topic overlap with Dillon's study (Dillon, 2001), the findings were similar. In 
both studies, respondents reported a similar history with respect to drug use, and criminal activity and drug misuse were interlinked. Whereas Dillon (2001) asked respondents about their experience and perceptions of different harm reduction interventions, the present study asked what the prison authorities could do to address drug misuse. In both studies, respondents described similar shortcomings of the current service to address drug misuse in the prison environment.

It is timely for policy makers, researchers and clinicians working in prisons to ensure that being in prison does not add unnecessarily to the health risks of an already disadvantaged population. Community drug treatment services in Ireland have evolved considerably over the last decade and needle exchange and methadone maintenance are widely available. The Irish prison health care system has not kept pace with this change, but this is not unique, as few prison health care services implement such measures (Dolan, Hall, \& Wodak, 1998; European Monitoring Centre for Drugs and Drug Addiction, 2000; Farrell, Howes, Vester, \& Davoli, 1999). The research available on Irish prisons (Allwright et al., 2000; Dillon, 2001; Long et al., 2001; O'Mahony, 1997) suggests a need to consider provision of a broad range of harm reduction measures in Irish prisons. Sterilising tablets, needle exchange, methadone maintenance, methadone detoxification and drug free units have been presented as harm reduction methods that could be used in prisons. However, prior to their introduction, the evidence supporting the use of each of these harm reduction methods needs to be examined in the prison setting. There is considerable evidence supporting methadone maintenance (Marsch, 1998) and needle exchange (Goldberg, Cameron, \& McMenamin, 1998; Hurley, Jolley, \& Kaldor, 1997; Smyth, Keenan, \& O'Connor, 1999) in community settings, but only limited evidence of their effectiveness in preventing hepatitis $\mathrm{C}$ either in community settings or in the prison environment (Darke, Kaye, \& Finlay-Jones, 1998; Dolan et al., 1996; Dolan, Wodak, Mattick, \& Hall, 2000). Dolan et al. (2000) observed a lower incidence of anti-HCV in injectors randomly allocated to methadone maintenance in an Australian prison than in injectors randomly allocated to a methadone maintenance waiting list in the same prison. Small-scale prison studies have shown that bleach and needle exchange can reduce the spread of HIV in prisons (Goldberg et al., 1998; Kent, 1996) but these have not been evaluated for prevention of hepatitis $\mathrm{C}$.

The findings resulting from the quantitative surveys linked to this study (Allwright, Barry, Bradley, Long, \& Thronton, 1999; Allwright et al., 2000; Long et al., 2000, 2001; Thornton et al., 2000) appear to have been a catalyst for dialogue at a national level (Smyth et al., 2000). As a result there has been agreement by the prison services that a comprehensive and compassionate approach is required to address the use of illicit heroin and its consequences in the Irish prison setting. The Department of Justice, Equality and Law Reform has also recently instituted a Steering Group on Prison Based Drug Treatment Services. This
Steering Group has outlined 10 intentions that underpin the introduction of prison-based drug treatment services in Irish prisons (Irish Prison Service, 2000). Importantly, the Steering Group noted that "the prison service must replicate in prison, the level of medical and other supports available in the community for drug-dependent people to the maximum extent possible". This is a formal statement of support for the principle of equivalence of care with community drug services also supported by this study.

At present, there is a drug services plan proposed for five of the six Dublin prisons and an intention to approve a plan for the remaining prison. These services include prevention, detoxification, methadone maintenance, counselling and education. The intentions of the Steering Group for Prison Based Drug Treatment Services are encouraging, although the plan does not specify deadlines targets or budgets. As a result of the plan, methadone maintenance has been introduced in five Dublin prisons. Whereas by the end of January 2001, 24 prisoners were receiving methadone, by the end of August 2002, 338 prisoners were receiving methadone (Barry, personal communication). Given that on average, there are 700 persons with a history of heroin misuse in Dublin prisons on any single day, it is apparent that there is still much to do.

As regards the cleaning and provision of injecting equipment, there have been two attempts to introduce the formal distribution of full strength household bleach in Irish prisons but these have been rejected by the Prison Officers Association because they fear an increase in attacks on prisoners or prison officers. The provision of bleach tablet distributions in London prisons (Branigan, Hillsdon, \& Wellings, 2000) and needle exchange interventions in other prisons in Europe (Dolan, Rutter, \& Wodak, 2003; Nelles, Fuhrer, Hirsbruhher, \& Harding, 1998) has not led to an increase in attacks on prisoners or prison officers.

\section{Conclusion}

Substance misuse is an underlying problem for a large proportion of prisoners in the Republic of Ireland. There is a need to pilot harm minimisation interventions in Irish prisons, to examine their strengths and weaknesses in the Irish setting and to measure their effects, particularly in relation to the transmission of blood-borne viruses. It is important to note that the vast majority of prisoners view time in prison as an opportunity to address problems associated with substance misuse and that health professionals should not miss this opportunity.

\section{Acknowledgements}

The views expressed in this paper are those of the authors and do not necessarily reflect the views of the Department of Justice, Equality and Law Reform, Republic of Ireland. 
This study was conducted while the lead author was employed as a lecturer in international health at Trinity College Dublin. We thank those who participated in the survey. We hope that this research helps them achieve a drug treatment service in Irish prisons that is their statutory right. We also thank the management and officers working in Portlaoise Prison and Wheatfield Place of Detention for their complete and unbiased support. Thanks to the Department of Justice, Equality and Law Reform for allowing the team access to the prisons and to the Health Research Board in Ireland who provided part of the funding for this study. We also thank Ms. Ailbhe Mealy, Ms. Mary Durcan and Ms. Catherine Rice for transcribing the tapes and Ms. Deirdre Handy for editing the document. Thanks to Dr. Joseph Barry for providing insightful comments on the study findings and also providing practical support. Finally thank you to the staff at Trinity Court and Castle Street Health Centre for sharing their experiences of drug services and harm reduction.

\section{References}

Allwright, S., Barry, J., Bradley, F., Long, J., \& Thornton, L. (1999). Hepatitis B, hepatitis $C$ and HIV in Irish prisoners: Prevalence and risk. Dublin: The Stationery Office.

Allwright, S., Bradley, F., Long, J., Barry, J., Thornton, L., \& Parry, J. V. (2000). Prevalence of antibodies to hepatitis B, hepatitis C and HIV and risk factors in Irish prisoners: Results of a national cross sectional survey. British Medical Journal, 321, 78-82.

Appleton, J. (1995). Analysing qualitative interview data: Addressing issues of validity and reliability. Journal of Advanced Nursing, 22, 993-997.

Bird, A., Gore, S., Cameron, S., Ross, A., \& Goldberg, D. (1995). Anonymous HIV surveillance with risk factor elicitation at Scotland's largest prison, Barlinnie. AIDS, 9(7), 801-808.

Bird, A., Gore, S., Jolliffe, D., \& Burns, S. (1992). Anonymous HIV surveillance in Soughton Prison, Edinburgh. AIDS, 6(7), 725-773.

Branigan, P., Hillsdon, M., \& Wellings, K. (2000). An evaluation of the feasibility of introducing harm reduction techniques into prisons in England and Wales. Encouraging Health Promotion for Drug Users within the Criminal Justice System Conference incorporating the Fourth European Conference of Drug and HIV/AIDS Services in Prison. Hamburg, Germany.

Carvell, A., \& Hart, G. (1990). Risk behaviours for HIV infection among drug users in prison. British Medical Journal, 300, 1383-1384.

Crofts, N., Stewart, T., Hearne, P., Ping, X. Y., Breschkin, A. M., \& Locarnini, S. A. (1995). Spread of blood-borne viruses among Australian prison entrants. British Medical Journal, 310, 285-288.

Darke, S., Kaye, S., \& Finlay-Jones, R. (1998). Drug use and injection risk-taking among prison methadone maintenance patients. Addiction, 93(8), 1169-1175.

Denzin, N. (1989). The research act: A theoretical introduction to sociological methods. New York: McGraw Hill.

Dillon, L. (2001). Drug use among prisoners: An exploratory study. Dublin: The Health Research Board.

Dolan, K., Hall, W., \& Wodak, A. (1996). Methadone maintenance reduces injecting in prison. British Medical Journal, 312, 1162.

Dolan, K., Hall, W., \& Wodak, A. (1998). The provision of methadone within prison settings. In J. Ward, R. P. Mattick, \& W. Hall (Eds.), Methadone maintenance treatment and other opioid replacement therapies (pp. 379-395). Amsterdam: Harwood Academic Publishers.
Dolan, K., Rutter, S., \& Wodak, A. D. (2003). Prison based syringe exchange programmes: A review of international research and development. Addiction, 98, 153-158.

Dolan, K., Wodak, A., Mattick, R., \& Hall, W. (2000). A randomised control trial of the New South Wales prison methadone programme. Encouraging Health Promotion for Drug Users within the Criminal Justice System Conference incorporating the Fourth European Conference of Drug and HIV/AIDS Services in Prison. Hamburg, Germany.

European Monitoring Centre for Drugs and Drug Addiction. (2000). An overview on substitution treatment. In Reviewing current practice in drug substitution treatment in the European Union (pp. 135-145). Luxembourg: Office for Official Publications of the European Union.

Farrell, M., Howes, S., Vester, A., \& Davoli, M. (1999). Reviewing current practice in drug substitution treatment in Europe. London, Lisbon, Rome: National Addiction Centre, EMCDDA, Osservatorio Epidemiologico.

Goldberg, D., Cameron, S., \& McMenamin, J. (1998). Hepatitis C virus antibody prevalence among injecting drug users in Glasgow has fallen but remains high. Communicable Disease and Public Health, 1(2), 95-97.

Goldberg, D., Taylor, A., McGregor, J., Davis, B., Wrench, J., \& Gruer, L. (1998). A lasting public health response to an outbreak of HIV infection in a Scottish prison? International Journal of STD and AIDS, 9(1), 25-30.

Gore, S., Bird, A., Burns, S., Goldberg, D., Ross, A., \& Macgregor, J. (1995). Drug injection and HIV prevalence in inmates of Glenochill prison. British Medical Journal, 310, 293-296.

Gore, S., Bird, A., Burns, S., Ross, A., \& Goldberg, D. (1997). Anonymous HIV surveillance with risk-factors elicitation: At Perth (for men) and Cornton Vale (for women) prisons in Scotland. International Journal of STD and AIDS, 8, 166-175.

Haber, P., Parsons, S., Harper, S., White, P., Rawlinson, W., \& Lloyd, A. (1999). Transmission of hepatitis C within Australian prisons. Medical Journal of Australia, 171(1), 31-33.

Hurley, S. F., Jolley, D. J., \& Kaldor, J. M. (1997). Effectiveness of needle exchange programmes for prevention of HIV infection. The Lancet, 349, 1797-1800.

Hutchinson, S., Goldberg, D., Gore, S., Cameron, S., McGregor, J., McMenamin, J., \& McGavigan, J. (1998). Hepatitis B outbreak at Glenochil prison during January to June 1993. Epidemiology and Infection, 121(1), 185-191.

Irish Prison Service. (2000). Report of the steering group on prison based drug treatment services. Dublin: Department of Justice, Equality and Law Reform.

Kent, H. (1996). Should prisons ease drug prohibition to help reduce disease spread? Canadian Medical Association Journal, 155(10), 14891491.

Koch, T. (1994). Establishing rigour in qualitative research: The decision trail. Journal of Advanced Nursing, 19, 976-986.

Long, J., Allwright, S., Barry, J., Reaper-Reynolds, S., Thornton, L., \& Bradley, F. (2000). Hepatitis B, hepatitis C, and HIV in Irish prisoners: Part II. Prevalence and risks in committal prisoners 1999. Dublin: The Stationery Office.

Long, J., Allwright, S., Barry, J., Reaper-Reynolds, S., Thornton, L., Bradley, F., \& Parry, J. (2001). Hepatitis B, hepatitis C and HIV antibodies prevalence and risk factors in entrants to Irish prisons: A national survey. British Medical Journal, 323, 12091211.

Malliori, M., Sypsa, V., Psichogiou, M., Touloumi, G., Skoutelis, A., Tassopoulos, N., Hatzakis, A., \& Stefanis, C. (1998). A survey of blood borne viruses and associated risk behaviours in Greek prisons. Addiction, 93(2), 243-251.

Mariano, C. (1995). The qualitative research process. In Principles and practice of nursing research (pp. 463-491). Talbot. L. Missouri: Mosby-Year Book Inc. 
Marsch, L. (1998). The efficacy of methadone maintenance interventions in reducing illicit opiate use, HIV risk behaviour and criminality: A meta-analysis. Addiction, 93(4), 515-532.

Nelles, J., Fuhrer, A., Hirsbruhher, H., \& Harding, T. (1998). Provision of syringes: The cutting edge of harm reduction in prison. British Medical Journal, 317, 270-273.

O’Mahony, P. (1997). Mountjoy prisoners a sociological and criminological profile. Dublin: Department of Justice.

Poland, B. (1999). Transcription quality as an aspect of rigor in qualitative research. In A. Bryman \& R. Burgess (Eds.), Qualitative research: Part 3. Analysis and interpretation of qualitative data (pp. 13-32). London: Sage.

Polit, D., \& Hungler, B. (1999). Nursing research-principles and methods. Philadelphia: Lippincott.

Seidel, J. (1998). The ethnograph version 5.0. Thousand Oaks: Sage.

Smyth, B., Keenan, E., \& O'Connor, J. J. (1999). Evaluation of the impact of Dublin's expanded harm reduction programme on prevalence of hepatitis C among short term injecting drug users. Journal of Epidemiology and Community Health, 53, 434-435.
Smyth, B., Langkamp, H., Schmid, M., Green, S., Mckendrick, M., \& McCarthy, N. (2000). Health effects in prison. British Medical Journal, 321, 1406-1407.

Streubert Speziale, H. J., \& Rinaldi Carpenter, D. (2003). Qualitative research in nursing: Advancing the humanistic imperative. Philadelphia: Lippincott.

Taylor, A., Goldberg, D., Emslie, J., Wrench, J., Gruer, L., Cameron, S., Black, J., Davis, B., McGregor, J., Follett, E., Harvey, J., Basson, J., \& McGavigan, J. (1995). Outbreak of HIV infection in a Scottish prison. British Medical Journal, 310, 289-292.

Thornton, L., Barry, J., Long, J., Allwright, S., Bradley, F., \& Parry, J. (2000). Comparison between self reported hepatitis B, hepatitis C and HIV antibody status and oral fluid assay results in Irish prisoners. Communicable Disease and Public Health, 3(4), 253-255.

Turnbull, P. J., Dolan, K. A., \& Stimson, G. V. (1991). Prisons HIV and AIDS: Risks and experiences in custodial care. Horsham: AVERT.

Turnbull, P. J., Stimson, G. V., \& Stillwell, G. (1994). Drug use in prison. Horsham: AVERT. 